\title{
BRIDGING THE GAP
}

\section{DIFFERENTIAL ATTAINMENT IN LEADERSHIP ROLES IN THE UK NHS}

\section{PRE-WORKSHOP SCOPING PAPER}

\section{Abstract}

Aim - to review the evidence on differential attainment in leadership positions in the NHS and develop an expert consensus

In this review we will explore in-depth, the current data surrounding differential attainment in leadership roles in the UK NHS, possible reasons for these disparities and what interventions may address this inequality. This scoping review forms part of the Alliance for Equality in Healthcare Professions project on DA chaired by the British Association of Physicians of Indian Origin (BAPIO) and will be integrated into the Bridging the Gap project undertaken by BAPIO Institute for Health Research (BIHR).

Keywords Leadership roles; NHS; Differential Attainment

\author{
Saif Sait, Vijay Nayar, Dev Chauhan, \\ Sahana Rao, Geeta Menon \\ BAPIO Institute for Health Research, \\ Bedford, UK
}

Correspondence to geeta.menon@hee.nhs.uk

Cite as: Sait, S., Nayar, V., Chauhan, D., Rao, S., \& Menon, G. (2020) Differential attainment in Leadership roles in the UK NHS. Sushruta J Health Policy \& Opin vol 13; issue 3; epub 22.10.2020 DOI https://doi.org/10.38192/13.3.22

\begin{tabular}{ll}
\multicolumn{2}{l}{ Article Information } \\
\hline Submitted & 18.08 .2020 \\
Revised & 18.10 .2020 \\
Epub & 22.10 .2020
\end{tabular}

Open Access published under Creative Commons Licence v4.0 (CC-BY-ND-4.0)

\section{INTRODUCTION}

Differential attainment (DA) is the term used to describe a gap between different groups undertaking the same assessment based on factors related to gender, race, ethnicity, disability, protected characteristics as defined by the Equality Act of 2010, other socio-economic factors or country of origin. ${ }^{1}$ Differential attainment exists within and outside the medical profession extending to many walks of life and reflects inherent inequalities that exist in society. ${ }^{2}$

The UK National Health Service (NHS) has one of the most diverse workforces in the world with up to $40 \%$ from ethnic minority groups. However, the majority of leadership positions in the NHS are usually taken up by white employees rather than those from ethnic minorities and there exists similar disparities in respect to gender, sex, race and protected characteristics. ${ }^{3}$ Several studies have highlighted that white and ethnic minority staff have different experiences in terms of career progression. ${ }^{4}$ The NHS recruitment processes have been shown to favour white, male applicants. ${ }^{5}$ Compared with their white colleagues, ethnic minority staff are more likely to report bullying, harassment and referred to a formal disciplinary process. ${ }^{6}$ Ethnic minority doctors are also less likely to be shortlisted and appointed as consultants, indeed they hold $57 \%$ of staff grade or associate specialist posts. ${ }^{7}$ Ethnic minority consultants also earn $4.9 \%$ less than their white counterparts. ${ }^{8}$ This may be further compounded for female staff. Although women make up $77 \%$ of the NHS workforce, they only constitute $42 \%$ of NHS board 
members $^{9}$ and there exists a $23 \%$ gender pay gap across the NHS. ${ }^{10}$

In this review we will explore in-depth, the current data surrounding differential attainment in leadership roles in the UK NHS, possible reasons for these disparities and what interventions may address this inequality. This scoping review forms part of the Alliance for Equality in Healthcare Professions project on DA chaired by the British Association of Physicians of Indian Origin (BAPIO) and will be integrated into the Bridging the Gap project undertaken by BAPIO Institute for Health Research (BIHR).

\section{Why is this important?}

The UK NHS was founded upon the principle that every person is treated fairly, equally and free from discrimination regardless of their 'gender, race, disability, age etc.'11 There is strong evidence that diversity and equality in leadership has a positive impact on the performance and culture of an organisation, ${ }^{12}$ including non-profit organisations. ${ }^{13}$ Further benefits of an equal and representative leadership is a widening of the leadership talent, better understanding or engagement with local communities or partners and priorities. ${ }^{14}$ It can help to cultivate a culture of care and values, ensuring that the NHS adheres to its pledges and guiding principles. Furthermore, it has been shown to help deliver a better standard of care with more sensitivity to patients and their families. ${ }^{14}$ As the NHS is perpetually in a workforce challenge, improving diversity and inclusivity will play an important role in becoming a better place to work and develop careers. ${ }^{15}$

What are the latest figures?

In 2014, Roger Kline assessed the progress of racial equality in the NHS following the NHS Race Equality Action Plan. ${ }^{16}$ His survey of the leadership in London's NHS trusts showed a large gap between the NHS Trust's governance and leadership and the communities they served. ${ }^{17,5}$ The report found that despite years of support for initiatives aimed at addressing barriers to the progression of Black Asian and Minority Ethnic (BAME) staff, little progress had been made. ${ }^{5}$ In 2015, the Workforce Race Equality Standard (WRES) was created to improve the transparency of data, increase awareness and tackle the inequalities. ${ }^{18-19}$ Besides, NHS England and NHS improvement (NHSEI) have committed to monitoring their performance on race equality. ${ }^{20} \mathrm{In}$ March 2020, Sir Simon Stevens announced that NHSEI would be committing to a target of $19 \%$ representation of ethnic minority employees at every pay band within the joint organisation by 2025 to reflect the make-up of the wider NHS, where $19.7 \%$ of NHS trust and commissioning staff are from an ethnic minority background. 6,21

Table 1: Proportion of BAME staff in the NHS over time \{ref\}

\begin{tabular}{|l|c|c|c|c|}
\hline & 2016 & 2017 & 2018 & 2019 \\
\hline BME staff percentage & $17.7 \%$ & $18.1 \%$ & $18.9 \%$ & $19.7 \%$ \\
\hline BME VSM percentage & $5.4 \%$ & $5.3 \%$ & $5.8 \%$ & $6.5 \%$ \\
\hline Gap & $12.3 \%$ & $\mathbf{1 2 . 8} \%$ & $\mathbf{1 3 . 2} \%$ & $13.3 \%$ \\
\hline
\end{tabular}

Data source: NHS workforce statistics website.

The most recent analysis of the national data was carried out by WRES in NHS Trusts. ${ }^{6}$ Here we evaluate the key results for the following five measures:

- Representation of ethnic minorities in leadership roles

- Impact of gender in leadership roles

- Impact of Ethnicity and Gender on Pay

- Clinical Excellence awards 
Ethnic minorities in leadership roles

Ethnic minorities are over-represented in NHS Agenda for Change (AfC) pay band 5 and significantly underrepresented above band 8a, which includes very senior managers (VSM) i.e. chief executives, executive directors, and other senior managers with board-level responsibility. As the pay bands increase there is a demonstrable reduction in the proportion of ethnic minority staff, from $24.5 \%$ in band 5 to $6.5 \%$ at very senior manager levels (Figure 1). ${ }^{6}$ This is significantly lower than the $19.7 \%$ of NHS staff who are from BAME groups across the country.

Figure 1: Number of staff by AfC pay bands (8a to VSM) and ethnicity for all NHS trusts and CCGs (2019). ${ }^{6}$

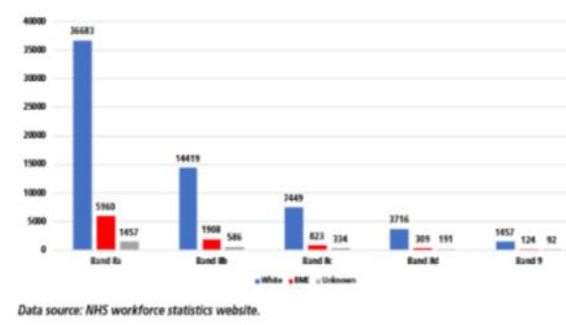

Table $1^{6}$ does show that there has been an increase in the proportion of VSM staff in NHS Trusts from $5.4 \%$ in 2016 to $6.5 \%$ in 2019 . However, the proportion of BAME staff increased from $17.7 \%$ in 2016 to $19.7 \%$ in this period, which has led to a greater differential between the proportion of overall BAME staff and representation at VSM (Table 2). ${ }^{6}$ This highlights the need to accelerate opportunities for BAME staff representation at senior levels across the workforce, as set out in the NHS Long Term Plan.
Table 2: Number of VSM staff in NHS trusts and CCGs in England 2016-2019. ${ }^{6}$

\begin{tabular}{|l|c|c|c|c|}
\hline \multicolumn{1}{|c|}{ Ethnicity } & $\mathbf{2 0 1 6}$ & $\mathbf{2 0 1 7}$ & $\mathbf{2 0 1 8}$ & $\mathbf{2 0 1 9}$ \\
\hline White & 1,727 & 1,741 & 1,783 & 1,869 \\
\hline BME & 110 & 108 & 122 & 143 \\
\hline Unknown & 197 & 185 & 204 & 200 \\
\hline \% BME & $\mathbf{5 . 4 \%}$ & $\mathbf{5 . 3 \%}$ & $\mathbf{5 . 8} \%$ & $\mathbf{6 . 5} \%$ \\
\hline
\end{tabular}

Data source: NHS workforce statistics website.

Overall, there has also been an increase in the percentage of BAME board members within NHS Trusts from $7.4 \%$ in 2018 to $8.4 \%$ in 2019 . There has also been a decrease in the proportion of NHS Trusts with no BAME representation on the board, from 96 in 2018 to 73 in 2019. 6 More data is required for primary care along with more granularity of the data from secondary care. This will help us understand further the extent of this differential representation.

Impact of Gender in leadership roles

Ruth Sealy's report, 'NHS women on boards: 50:50 by 2020 ' found that although women make up $77 \%$ of the NHS workforce, the percentage of women on NHS boards is only $42 \%$. Currently, there are still 209 NHS Trust boards that do not demonstrate gender equality in the constitution of their boards. The report suggests the need for an additional 500 women in NHS Trust boards would be required to achieve gender balance by $2020 .{ }^{9}$

Currently, no data is showing the percentage of BAME women that hold leadership positions. ${ }^{22}$

The Athena Swan Charter is a framework which is used across the globe to support and transform gender equality within higher education (HE) and research. Established in 2005 to encourage and recognise the commitment to advancing the careers of women in science, technology, engineering, maths and medicine (STEMM) employment, the Charter is now being used across the globe to address gender equality more broadly, and not just barriers to progression that affect women. 
A study looking at the effectiveness of the Athena Swan initiative found that $90 \%$ of Athena Swan champions agreed that it had impacted positively on gender issues and $65 \%$ agreed that there had been a positive impact on women's career progression. ${ }^{23}$ Women felt that the Athena Swan had helped to improve their self-confidence and enhanced their leadership skills. The initiative also was found to impact positively on institutional practices by helping them to identify challenges to gender equality, supporting women returners and facilitating factors for delivering institutional change. ${ }^{23}$ There are fears however that the Athena Swan initiative may be scrapped.

Impact of Ethnicity \& Gender on pay

NHS Digital equality and diversity statistics show that in 2019, 34.1\% of the consultants in England were from BAME groups compared to $56.4 \%$ white. ${ }^{24}$ Doctors from ethnic minority backgrounds, working in the same roles are paid substantially less than their white colleagues. ${ }^{8}$ In senior positions, such as consultant posts, BAME staff earn 2.3-3.3\% less than their white colleagues. While in management positions African, Caribbean and British black managers earn $14.2 \%$ less and Asian managers $7.9 \%$ less than their white colleagues. ${ }^{8}$

Currently, women make up $36 \%$ of consultants in the UK, although they represent two-thirds of doctors in training. The current gender pay gap for women doctors is $17 \%$, while the overall NHS gender pay gap is $23 \% .{ }^{10}$ There is no data on the gender pay difference related to BAME women.

\section{Clinical excellence awards}

Clinical Excellence Awards (CEAs) recognise and reward medical consultants, dentists and academic General Practitioners who provide evidence of clinical excellence and demonstrate achievements that are significantly over and above, what would normally be expected for their roles. The Advisory Council on Clinical Excellence Awards (ACCEA) is an independent body which reports annually the figures from the clinical excellence awards allocations. ${ }^{25}$
The ACCEA sub-committees currently have 336 members, with only $19.9 \%$ from BAME backgrounds. Out of the 14 medical vice-chairs and 14 chairs, only $14.3 \%$ and $7.1 \%$ were from BAME backgrounds, respectively (Table 3 ). Only $32.7 \%$ of the members and $7.1 \%$ of the medical chairs or vice-chairs were female (Table 4). ${ }^{25}$

Table 3: Sub-committee membership by ethnicity 25

\begin{tabular}{|c|c|c|c|c|}
\hline & White & BAME & | Total & \%BAME \\
\hline Arm's Length Body' & 16 & 3 & 19 & $15.8 \%$ \\
\hline Cheshire and the Mersey & 18 & 5 & 23 & $21.7 \%$ \\
\hline East Midlands & 16 & 5 & 21 & $23.8 \%$ \\
\hline East of England & 22 & 1 & 23 & $4.4 \%$ \\
\hline London Northeast & 17 & 5 & 22 & $22.7 \%$ \\
\hline London Northwest & 23 & 1 & 24 & $4.2 \%$ \\
\hline London South & 20 & 3 & 23 & $13.0 \%$ \\
\hline Northeast & 17 & 5 & 22 & $22.7 \%$ \\
\hline Northwest & 20 & 6 & 26 & $23.1 \%$ \\
\hline South & 17 & 4 & 21 & $19.1 \%$ \\
\hline Southeast & 17 & 4 & 21 & $19.1 \%$ \\
\hline Southwest & 21 & 3 & 24 & $12.5 \%$ \\
\hline West Midlands & 11 & 11 & 22 & $50.0 \%$ \\
\hline Yorkshire and the Humber & 15 & 7 & 22 & $31.8 \%$ \\
\hline Wales & 19 & 4 & 23 & $17.4 \%$ \\
\hline Total & 269 & 67 & 336 & $19.9 \%$ \\
\hline Medical Vice-Chairs & 12 & 2 & 14 & $14.3 \%$ \\
\hline Chairs & 13 & 1 & 14 & $7.1 \%$ \\
\hline
\end{tabular}

Table 4: Sub-committee membership by gender ${ }^{25}$

\begin{tabular}{|l|r|r|r|r|}
\hline Arm's Length Body & 10 & 9 & 19 & $47.4 \%$ \\
\hline Cheshire and the Mersey & 16 & 7 & 23 & $30.4 \%$ \\
\hline East Midlands & 14 & 7 & 21 & $33.3 \%$ \\
\hline East of England & 19 & 4 & 23 & $17.4 \%$ \\
\hline London Northeast & 14 & 8 & 22 & $36.4 \%$ \\
\hline London Northwest & 14 & 10 & 24 & $41.7 \%$ \\
\hline London South & 13 & 10 & 23 & $43.5 \%$ \\
\hline Northeast & 14 & 8 & 22 & $36.4 \%$ \\
\hline Northwest & 17 & 9 & 26 & $34.6 \%$ \\
\hline South & 14 & 7 & 21 & $33.3 \%$ \\
\hline Southeast & 16 & 5 & 21 & $23.8 \%$ \\
\hline Southwest & 18 & 6 & 24 & $25.0 \%$ \\
\hline West Midlands & 14 & 8 & 22 & $36.4 \%$ \\
\hline Yorkshire and the Humber & 16 & 6 & 22 & $27.3 \%$ \\
\hline Wales & 17 & 6 & 23 & $26.1 \%$ \\
\hline Total & 226 & 110 & 336 & $32.7 \%$ \\
\hline \multicolumn{4}{|l|}{} \\
\hline Medical Vice-Chairs & 13 & 1 & 14 & $7.1 \%$ \\
\hline Chairs & 13 & 1 & 14 & $7.1 \%$ \\
\hline
\end{tabular}


In 2018, from $36 \%$ of consultants from BAME backgrounds, made $22 \%$ of the applications and received only $16 \%$ of the awards. The number of BAME recipients and applicants was lower than in previous years, and the lowest since 2014. The likelihood of success for BAME applicants was 23.3\% compared to $31.8 \%$ for white applicants and the gap between the two had increased in the last few years (Table 5). ${ }^{25}$

The gender pay gap has been magnified further as majority of CEA awards (77.9\%) were given to men. There is an even bigger gap for the higher awards; (only 17\% for silver and gold and 14\% of platinum awards were given to women), amplified by the lower proportion of women making up the eligible consultant workforce (36\%) but the likelihood of success was similar, (Table 6). ${ }^{25}$

Table 5: BAME Applications and Success Rates for Clinical Excellence Awards (2013-2018) ${ }^{25}$

\begin{tabular}{|c|c|c|c|c|c|c|}
\hline BAME Ethnicity & 2013 & 2014 & 2015 & 2016 & 2017 & 2018 \\
\hline Applications & 302 & 280 & 221 & 234 & 237 & $\sqrt{22}$ \\
\hline Awards & 50 & 39 & 66 & 61 & 61 & 5 \\
\hline BAME Success & $16.6 \%$ & $13.9 \%$ & $29.9 \%$ & $26.1 \%$ & $25.7 \%$ & 23.3 ? \\
\hline White Success & $17.9 \%$ & $21.6 \%$ & $25.9 \%$ & $26.8 \%$ & $30.2 \%$ & 31.89 \\
\hline Gap & $-1.4 \%$ & $-7.7 \%$ & $4.0 \%$ & $-0.8 \%$ & $-4.4 \%$ & -8.59 \\
\hline
\end{tabular}

Table 6: 2018 applications and success rates for Clinical Excellence Awards by gender ${ }^{25}$

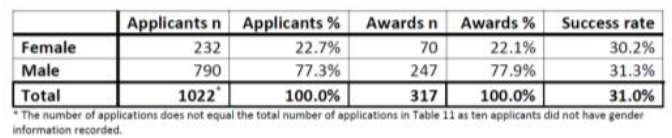

What are the potential causes?

Even though the data on DA is well known, there is evidence that progress in tackling these inequalities has been slow, and there are few if any, effective interventions. This responsibility is often left to local organisations with little national guidance or policy enablers. ${ }^{18}$ This is not an issue just within the NHS but is true for many walks of life and other industries.

The lack of diversity in the NHS leadership is mirrored nationally. An independent review by Sir John Parker found that only 8\% of Financial Times Stock Exchange (FTSE) top 100 company directors were from BAME backgrounds, out of a total of 1,087 positions. The Parker Review (2016) also found that over half of the 500 largest charities within England and Wales, had 'all-white governance' while 22.6\% had between 1-10\% BAME representation on their boards. ${ }^{17}$

\section{Causes of DA in leadership}

There is a range of factors which may lead to this lack of representation and prevent people from applying to leadership roles in the NHS. Research has shown that the causes of these differences are not usually individual factors but likely to be systemic.

Macro level

Although the NHS was founded on the principles of equality, societal or institutional racism is common and has been highlighted by the societal disparities revealed by the COVID-19 pandemic. ${ }^{26}$ Analysis by the Health Service Journal revealed $63 \%$ of UK health and social care workers, who died from COVID-19, were from BAME backgrounds. ${ }^{27}$ The latest WRES report from NHS England shows several factors which have led to BAME staff feeling more discriminated. These include: 6

- BAME staff reporting greater levels of bullying and harassment, discrimination at work and likelihood of having disciplinary hearings, compared to white colleagues 
- A much lower proportion of BAME staff believing that trusts provide equal opportunity for career progression, compared to white colleagues

- Greater likelihood of white applicants being appointed to all jobs, leadership or senior managerial positions, compared to those from BAME backgrounds.

Bullying \& harassment and likelihood of being referred for disciplinary hearings

The WRES 2019 report shows that the relative likelihood for BAME staff entering a formal disciplinary hearing compared to white staff has reduced from 1.56 in 2016 to 1.22 in $2019 .{ }^{6}$ The Fair to Refer report ${ }^{28}$ by the UK General Medical Council found that there may be several reasons for this. Doctors from ethnic backgrounds, especially those trained outside the UK were not given the support they needed by their supervisors/ managers and colleagues and are more likely to end up being blamed and facing disciplinary action when things go wrong. ${ }^{29}$ The report recommended that each organisation should provide frequent, honest feedback, support, and integrating staff within teams. There was also a need for more senior leadership role models, being representative of the diversity of the whole NHS workforce will help. ${ }^{28}$

Other indicators in the WRES 2019 report, however, have deteriorated. ${ }^{6}$ For example, $29 \%$ of ethnic minority staff report having experienced bullying, harassment, or abuse from other staff in the past 12 months, compared to $24.2 \%$ of white colleagues, up from $27 \%$ in 2016 . Over $15 \%$ of ethnic minority staff report experiencing discrimination at work from a manager, team leader or another colleague, up from $13 \%$ in 2017 and is more than double the proportion of white colleagues reporting discrimination (6.4\%).

Equal opportunity for career progression

Only $69.9 \%$ of BAME staff believed that their Trust provided equal opportunities for career progression compared with $86.3 \%$ of their white colleagues, which has dropped in 2018 (Table 7). ${ }^{6}$
Table 7: Percentage of staff believing that their trust provides equal opportunities for career progression or promotion 2015-2018. ${ }^{6}$

\begin{tabular}{|l|c|c|c|c|}
\hline & 2015 & 2016 & 2017 & 2018 \\
\hline BME & $73.4 \%$ & $73.2 \%$ & $71.9 \%$ & $69.9 \%$ \\
\hline White & $88.3 \%$ & $87.8 \%$ & $86.8 \%$ & $86.3 \%$ \\
\hline
\end{tabular}

In a survey of ethnic minorities working in the NHS, by King's fund respondents were asked,

'How would you describe your experience of being an ethnic minority within the NHS?' One of the responses was:

'Being a BAME person in the NHS has many challenges with limited job opportunities to progress to junior/senior management. The biggest impact on me is the feeling of being silent and not good enough to lead/manage a team regardless of one's knowledge or experience or qualifications ${ }^{\prime 18}$

Likelihood of being appointed

Across the NHS in 2019, the relative likelihood of white applicants being successfully appointed across all posts was 1.46, compared to BAME applicants, dropping from 1.57 in 2016, although the gap remains significant. ${ }^{6}$ Yvonne Coghill, the VicePresident of the Royal College of Nursing and director of WRES, reported in an interview for the British Medical Journal, that she applied unsuccessfully for five directors of nursing posts. The people who got the jobs were 'invariably white' and she mentions how this made her,

"question herself, rather than question the system." 30

A study exploring consultant appointments found that there were $46 \%$ white, compared to $33.4 \%$ of Chinese and $30.6 \%$ of black doctors, which was significantly out-of-proportion to the proportions of doctors from each of these ethnic groups in the same organisations. ${ }^{31}$ Ethnic minority doctors were more likely to apply for more consultant posts before being successful than white doctors (1.66 versus 
1.29). ${ }^{32}$ Public attitudes to are often entrenched in racial profiling or discrimination as there have been many reported cases of patients asking to see ' $a$ white doctor'.

\section{MESO LEVEL}

\section{Lack of opportunities}

Research has shown that many employees from a BAME background do not have access to contacts, networks, or prospects to successfully climb the career ladder. ${ }^{33}$ Guidance on how to apply for roles, mentoring and development programmes may help to tackle this. There is little available data from applicants with other protected characteristics or disabilities.

Lack of role models

The lower representation of women or BAME role models in leadership positions is yet another factor limiting the progression in balancing these inequalities, where a vicious cycle perpetuates the lack of representation of women or BAME aspirants in leadership roles. A report by King's Fund, 'Workforce race inequalities and inclusion in NHS providers' ${ }^{18}$ highlighted some of the challenges and impacts that a lack of diversity in leadership positions in the NHS can have.

'I don't see anybody of my kind there [on the board], it's just all white faces. So, they don't fully understand, I don't think they understand the difficulties that BAME people go through, you know, which is slightly different to our white colleagues. And so our profile is a lot lower because there's not many of us.' 18

This is also demonstrated when there is diversity in leadership roles within an organisation.

'I think seeing a more diverse board of directors shows that equality is working. Yes, I think it would inspire other staff. You'll find that there is somebody you can speak to, somebody you can relate to, somebody to talk to' 18
MICRO LEVEL

Individual factors that may lead to BAME staff not applying for leadership roles include:

- a lack of awareness of the NHS governance system or of how the role works, and

- the lack of support, mentorship or potential self-confidence due to discrimination, the experience of bullying or harassment or trust in senior leadership.

- There may be socio-economic factors. ${ }^{14}$

\section{POTENTIAL SOLUTIONS}

Macro level - organisational engagement

- Benchmarking - An evaluation of WRES showed that the impact of its work depends on how well trusts engaged with the race equality agenda before the standards were introduced. ${ }^{19}$ Thus, it is questionable how well the annual reporting of WRES alone, will help to improve racial inequality in the NHS. Further data on primary care and a detailed breakdown of secondary care consultants are required as well as on representation of BAME women, and extending to other protected characteristics in leadership positions. A Charter mark for DA in line with Athena Swan innovation may be beneficial.

- $\quad$ Setting targets - The NHSEI have produced 'The model employer report: Increasing black and minority ethnic representation at senior levels across the $N H S^{\prime}$ to explore ways of tackling the low representation of BAME in leadership positions. ${ }^{34}$ One of the aspirations is to reach equality in BAME representation across the workforce by 2028. For example, in the VSM category, the 
model will mean, that one in every four of all VSM staff recruited in NHS Trusts, are from a BAME background. This is, therefore, an additional 41 BAME VSM recruits across all NHS Trusts per year. The plan recommends that organisations discuss their implementation innovations openly at board meetings and develop an action plan. ${ }^{34}$

- Cultural Transformation - The model also mentions how the NHS is planning to tackle the under-representation of BAME in leadership positions with a cultural and transformational change across the entire workforce. The focus will be on growing and supporting the existing BAME talent from within the NHS and attracting talent from outside of the NHS.

Meso level

- Coaching \& Mentoring - The plan is to develop support interventions such as mentoring and coaching and hold organisations to account. Data and progress will be monitored and benchmarked for continuous improvement. ${ }^{34}$

Figure 2: Evidence-based model for improving BAME representation across the NHS workforce. ${ }^{34}$

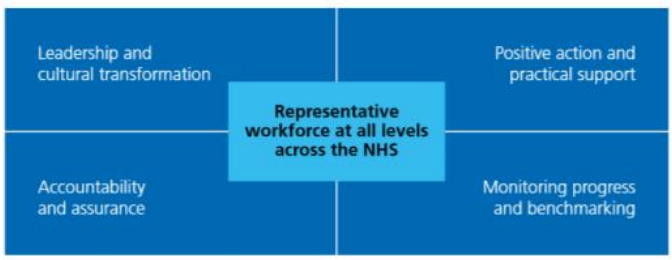

- Initiatives such as Athena Swan.. ${ }^{23}$ Possibility of expanding or tailoring this to BAME staff.

- Leadership development - programmes for ethnic minority staff in the NHS aspiring to progress to more senior roles

- 'Stepping Up' and 'Ready Now' run by the NHS Leadership Academy - see www.leadershipacademy.nhs.uk/ programmes/the-stepping-up-programme and www.leadershipacademy.nhs.uk/ programmes/the-ready-now-programme respectively);

- $\quad$ the 'Building Leadership for Inclusion' (BLFI) programme led by the NHS Leadership Academy, which aims to accelerate and strengthen NHS capacity for inclusive leadership development, among other things (see www.leadership academy.nhs.uk/resources/inclusionequality-and-diversity/blfi-2);

- Regional talent management functions should be rebuilt in the new joint NHS England and NHS Improvement regional teams. ${ }^{4}$ One example of this was by Bradford NHS Trust who developed a 'Moving Forward' Programme. The programme aimed to equip staff in band 5 and 6 roles with leadership skills and learning experience to help them apply for and be successful in securing more senior positions. It shows that if the trust is willing to accept and tackle the problem then a solution can be found. The programme has now become available to other trusts in the local area. ${ }^{18}$

- An independent task force launched by the NHS confederation to support NHS organisations to increase non-executive diversity on their boards and governing bodies. ${ }^{14}$ Various independent consultancies offering support on recruiting for diversity and implementing equality, diversity and inclusion interventions

- $\quad$ Staff Networks - The NHS has numerous staff networks that promote equality. These include voluntary organisations such as BAPIO, which 
was formed to tackle inequality and differential attainment. BAPIO was created in 1996 and has gone on to be a significant influencer in supporting several other voluntary healthcare bodies, shaping organisational and governmental policy as well as expanding its remit to include all healthcare professionals and mutually supportive partnerships with key institutions. ${ }^{35,36}$ There are several key benefits to staff networks, the main one being that it can help promote a sense of solidarity and create a 'psychological safe space' for discussing aspects of inclusion, diversity and equality. ${ }^{17}$

- Equality and diversity champions, BAME groups and representatives at every organisation who have direct links to the board with an accountable Non-executive member.

- Other key benefits, highlighted by the NHS England Survey, include creating a pipeline of talent and potential future leaders and fostering empathy and collaboration among staff. ${ }^{37}$ However some staff feel that these groups can lead to segregation. Others feel that taking actions to progress race equality should not be the role of members that have been on the receiving end of discrimination and marginalisation in the first place. ${ }^{17}$

- Unconscious bias - This is training that can raise awareness of issues around equality and diversity. ${ }^{38}$ However, it can lead to mixed results and may take the focus away from how well an organisation as a whole is performing rather than on individuals addressing their biased behaviours. ${ }^{17}$ Universal access to leadership courses that increase awareness of senior leaders of the inequalities and measures to tackle the lack of diversity.

\section{MICRO LEVEL}

- $\quad$ Reverse Mentoring - An intervention which is focused on promoting inclusion and diversity at an individual level is reverse mentoring, which involves pairing a junior employee with a senior one (ideally from different backgrounds). The aim is to address 'advantage blindness' among leaders through sharing experiences. ${ }^{39}$ There are no formal evaluations of the benefit of this, but the experience of senior leaders who have taken part appears to have been a positive one.

- In accessing non-mandatory training and continuous professional development.

What would race equality and inclusion 'success look and feel like?

The survey by King's Fund showed that there were several ways staff felt more included in their organisations. ${ }^{18}$ These included:

- a reduction in levels of bullying, harassment, and abuse

- a reduction in the percentage of ethnic minority staff referred to a formal disciplinary process

- $\quad$ an increase in the representation of ethnic minority staff overall (including in leadership positions)

- an increase in the percentage of ethnic minority staff accessing non-mandatory training and continuous professional development.

'And I think... having some of those changes at the senior leadership has given a sense of... I hate to use this word, a sense of hope for people who might feel, oh, gosh, it's always the same face at the top, you know, it's always male or it's always white male, you know. And the trust is so diverse, so our leaders must represent that diversity, which I think it does, and it continues to examine itself, I would say' 18

\section{Conclusion}

This scoping review of DA in Leadership roles highlights that so far, no NHS Trust has achieved equality in offering a genuine level playing field for all of its employees to achieve their potential. The disparities in terms of ethnicity or gender continue to be significant and improvements are minuscule. Initiatives such as WRES and NHSEI action plans are still to be implemented or enforced at the local or regional level. There is little or no data for the impact of intersectionality (eg BAME and gender) or the impact of disability or any of the other protected characteristics in leadership. There is a significant 
and persistent disparity with culture, support, mentorship and ingrained discrimination or bullying and harassment for a large proportion of staff. The handling of disciplinary proceedings, referral to the regulators and support to achieve recognition for clinical excellence awards is poor in local and national levels. There are few, if any, role models in local and national bodies, that represent the diversity of the NHS workforce. Initiatives such as WRES and NHSEI action plans lack teeth and there are no accountability or punitive action for organisations that continue to fail these standards. There silence and lack of leadership at the national level and hardly any policy enablers. ${ }^{40}$

Even after the poor outcomes for BAME patients or healthcare staff that has been highlighted in the COVID-19 pandemic, there is still a lack of serious commitment from policy leaders and many organisations remain in dormancy. The Equality, diversity and inclusion incentives are inadequate and lack of accountability or sanctions remains a major policy weakness.

\section{Future research}

Application of Athena Swan type of principles to tackle DA may help to increase awareness, transparency but ultimately sanctions may be necessary to shift this impasse.

Initiative to improve access to support, mentorship and opportunities for leadership and reduce differential attainment in the healthcare settings will need to be funded and explored by robust research

Initiatives to improve applications for Clinical excellence awards will need to be undertaken along with serious mentorship and diversification of the assessment boards

\section{References}

1. Shah R, Ahluwalia S. The challenges of understanding differential attainment in postgraduate medical education. Br J Gen Pract.
2019 Aug 29;69(686):426-427.

doi: 10.3399/bjgp19X705161

2. Mountford-Zimdars, A.K., Sanders, J., Jones, S., Sabri, D. and Moore, J., 2015. Causes of differences in student outcomes, Higher Education Funding Council for England. https://dera.ioe.ac.uk/23653/1/HEFCE 2015 diffout.pdf

3. Milner A, Baker E, Jeraj S, et al. Race-ethnic and gender differences in representation within the English National Health Service: a quantitative analysis BMJ Open 2020;10:e034258. http://dx.doi.org/10.1136/b mjopen-2019-034258

4. West, M., Dawson, J. and Kaur, M., 2015. Making the difference: Diversity and inclusion in the NHS. The Kings Fund. https://www.kingsfund.org.uk/sites/defau lt/files/media/Mandip Kaur.pdf

5. Kline, R., 2014. The snowy white peaks of the NHS: a survey of discrimination in governance and leadership and the potential impact on patient care in London and England. https://doi.org/10.22023/mdx.126404 $\underline{21 . v 1}$

6. WRES Implementation Team (2020). NHS Workforce Race Equality Standard: 2019 data analysis report for NHS trusts [online]. NHS England website. Available at: https://www.england.nhs.uk/publication/ workforce-race-equality-standard-datareporting-2019 (accessed on 27 February 2020).

7. Kmietowicz Zosia, Ladher Navjoyt, Rao Mala, Salway Sarah, Abbasi Kamran, Adebowale Victor et al. Ethnic minority staff and patients: a health service failure BMJ 2019; 365 :12226 https://doi.org/10.1136/bmj.12226

8. Moberly Tom. Doctors from ethnic minority backgrounds earn less than white colleagues BMJ 2018; 363 :k5089 doi: https://doi.org/10.1136/bmj.k5089

9. Sealy, R., NHS Women on Boards by 2020. NHS, 2017 https://www.nhsemployers.org//media/Employers/Publications/NHS-Womenon-Boards-report.pdf

10. Department of Health and Social Care (2019) 'New data on gender pay gap in medicine.' GOV.UK website. Available at: https://www.gov.uk/government/news/new -data-on-gender-pay-gap-in-medicine

11. Department of Health and Social Care (2015). 'The NHS Constitution for England'. GOV.UK website. Available 
at: https://www.gov.uk/government/publication s/the-nhs-constitution-for-england/ the-nhsconstitution-for-england

12. Rimmer Abi. NHS must do more to tackle white male dominance of leadership roles, Labour Party says BMJ 2016; 354 :i4610 doi: https://doi.org/10.1136/bmj.i4610

13. Medina, S., 2017. The diversity gap in the nonprofit sector.

https://philanthropynewsdigest.org/columns/th e-sustainable-nonprofit/the-diversity-gap-in-thenonprofit-sector

14. Confederation, N.H.S., 2019. Chairs and nonexecutives in the NHS: The need for diverse leadership. https://www.nhsconfed.org//media/Confederation/Files/Publications/Chair s-and-non-executives-in-the-NHS.pdf

15. Beech, J., Bottery, S., Charlesworth, A., Evans, H., Gershlick, B., Hemmings, N., Imison, C., Kahtan, P., McKenna, H., Murray, R. and Palmer, W., 2019. Closing the gap: key areas for action on the health and care workforce. London, UK: Kings Fund. https://www.nuffieldtrust.org.uk/research /closing-the-gap-key-areas-for-action-on-thehealth-and-care-workforce

16. DEPARTMENT OF HEALTH. (2004). Race Equality Action Plan.

Available: http://webarchive.nationalarchives.go v.uk/+/http://www.

dh.gov.uk/en/Publicationsandstatistics/Bulletins /DH_4072494.

17. Bolden, R., Adelaine, A., Warren, S., Gulati, A., Conley, H. and Jarvis, C., 2020. Inclusion: The DNA of leadership and change. https://uwerepository.worktribe.com/output/852067/inclu sion-the-dna-of-leadership-and-change

18. Ross, S., Jabbal, J., Chauhan, K., Maguire, D., Randhawa, M., and Dahir, S., 2020. Workforce race inequalities and inclusion in NHS providers The King's Fund website. Available at: https://www.kingsfund.org.uk/sites/default/ files/2020-07/workforce-race-inequalitiesinclusion-nhs-providers-july2020.pdf

19. Dawson J, Sampson F, Rimmer M, Buckley Woods H, West M, Nadeem S (2019). Evaluation of the NHS Workforce Race Equality Standard (WRES) [online]. NHS England website. Available at: https://www.england.nhs.uk/publication/eva luation-of-the-nhs-workforce-race-equalitystandard-wres

20. NHS Equality and Diversity Council (2019b). Equality and Diversity Council: narrative and terms of reference [online]. NHS England website. Available at:

www.england.nhs.uk/publication/equalityanddiversity-council-narrative-tor

21. NHS England (2020a). 'NHS England chief pledges "head office" will match diversity of health service'. Press release, 5 March. Available at: https://www.england.nhs.uk/2020/03/nhschief-pledgeshq- will-match-diversity-of-healthservice

22. Equality and Human Rights Commission (2011) Sex and Power. Equality and Human Rights Commission, London. https://www.equalityhumanrights.com/ en/publication-download/sex-and-power-2011

23. Rosser SV, Barnard S, Carnes M, Munir F. Athena SWAN and ADVANCE: Effectiveness and lessons learned. Lancet 2019. 9;393(10171):604-608 DOI: https://doi.org/10.1016/S01406736(18)33213-6

24. NHS Digital 2019. NHS Workforce statistics September 2019 https://digital.nhs.uk/data-andinformation/publications/statistical/nhsworkforce-statistics/september-2019

25. Advisory Committee on Clinical Excellence Awards. Annual report covering the 2018 awards round.

2019. https://assets.publishing.service.gov.uk/g overnment/uploads/system/uploads/attachmen t data/file/867066/ACCEA Annual Report 2019 .pdf

26. Bamrah J, Chand K. The best birthday present for the NHS? An end to its institutional racism [Internet]. the Guardian. 2020 [cited 19 July 2020]. Available from: https://www.theguardian.com/society/20 20/jul/03/best-birthday-present-nhs-endinstitutional-racism

27. Cook T, Kursumovic E, Lennane S. Exclusive: deaths of NHS staff from covid-19 analysed. Health Service Journal. 2020 Apr 22;22. https://www.hsj.co.uk/exclusive-deathsof-nhs-staff-from-covid-19analysed/7027471.article

28. Atewologun, D., Kline, R. and Ochieng, M., 2019. Fair to Refer. Reducing disproportionality in fitness to practise concerns reported to the GMC. https://www.gmc-uk.org/_media/documents/fair-to-refer-report-pdf79011677 pdf-79021583.pdf

29. Majid Aisha. What lies beneath: getting under the skin of GMC referrals BMJ 2020; 368 :m338 doi: https://doi.org/10.1136/bmi.m338 
30. Jones Helen. Yvonne Coghill: cultural transformation through conversation BMJ 2020; $368: m 474$

doi: https://doi.org/10.1136/bmj.m474

31. Rimmer Abi. White doctors are still overrepresented in top NHS jobs, study finds BMJ 2020; 368 :m571 doi: https://doi.org/10.1136/bmj.m571

32. Linton Samara. Taking the difference out of attainment BMJ 2020; 368 :m438 doi: https://doi.org/10.1136/bmj.m438

33. Nath, V. Are opportunities still limited for black and minority staff in health care leadership? 2016. The King's Fund website. Available at: https://www.kingsfund.org.uk/blog/2016/04 /BME-staff-healthcare-leadership

34. NHS Improvement., 2019. A Model Employer: Increasing black and minority ethnic representation at senior levels across the NHS. Available at: https://www.england.nhs.uk/wpcontent/uploads/2019/01/wres-leadershipstrategy.pdf

35. McGregor-Smith R (2017). Race in the workplace: the McGregor-Smith review [online]. GOV.UK website. Available at: https://www.gov.uk/government/publication $\underline{\text { s/race-in-the-workplace-the-mcgregorsmith- }}$ review

36. Chakravorty, I., Bamrah, J., \& Mehta, R. (2020). A Rainbow Paper - Tackling inequalities, a neoliberal order in a world after Corona. Sushruta Journal of Health Policy \& Opinion, 13(3). DOI https://doi.org/10.38192/13.3.14

37. ENGLAND, NHS., 2017. Improving through inclusion Supporting staff networks for black and minority ethnic staff in the NHS. https://www.england.nhs.uk/publication/i mproving-through-inclusion-supporting-staffnetworks-for-black-and-minority-ethnic-staff-inthe-nhs/

38. Atewologun, D., Cornish, T. and Tresh, F., 2018. Unconscious bias training: An assessment of the evidence for effectiveness. Equality and Human Rights Commission Research Report Series. https://www.equalityhumanrights.com/si tes/default/files/research-report-113unconcious-bais-training-an-assessment-of-theevidence-for-effectiveness-pdf.pdf

39. Fuchs B (2019). 'Talking leadership: Ben Fuchs on "advantage blindness"'. The King's Fund website. Available at: https://www.kingsfund.org.uk/publications/t alking-leadership-advantage-blindness
40. Coghill Y (2020). “'Our NHS people matter” - five years of the Workforce Race Equality Standard (WRES)'. Blog. Available at: https://www.kingsfund.org.uk/blog/2020/02 /five-years-workforce-raceequality-standard$\underline{\text { wres }}$ 